\title{
The relationship between smile attractiveness and esthetic parameters of patients with lateral agenesis treated with tooth recontouring or implants
}

This article was published in the following Dove Press journal:

Clinical, Cosmetic and Investigational Dentistry

14 December 2012

Number of times this article has been viewed

\section{Luciana Manzotti \\ De-Marchi' \\ Núbia Inocencya Pavesi \\ Pini $^{2}$ \\ Renata Corrêa Pascotto 3 \\ 'Department of Dentistry, University Center of Maringá-CESUMAR, \\ Maringá-PR/Brazil; 'Piracicaba Dental School, State University of Campinas, Piracicaba-SP/Brazil; ${ }^{3}$ Department of Dentistry, State University of Maringá, Maringá-PR/Brazil}

Correspondence: Renata Corrêa Pascotto Universidade Estadual de Maringá - UEM Departmento de Odontologia Avenida Mandacaru, 1550 - S08 CEP: 87083-I70, Maringá, PR, Brasil Tel +55 442101905 I

Email renatapascotto@gmail.com.br
Background: The purpose of this study was to associate smile esthetic judgment with dentofacial attributes of patients with unilateral and bilateral agenesis of maxillary lateral incisors treated with recontouring of canines or implants and patients with no agenesis (control).

Material and methods: Forty-six participants were divided into two groups: those treated with recontouring $(\mathrm{N}=26)$ and those treated with implants $(\mathrm{N}=20)$. The participants in the control group $(\mathrm{N}=22)$ were selected among dentistry students at the State University of Maringá, Brazil. Photographs of posed smiles $(17 \mathrm{~cm} \times 10 \mathrm{~cm})$ were evaluated with a $100-\mathrm{mm}$ Visual Analog Scale. Smile attractiveness was judged by two groups: laypersons and dentists $(\mathrm{N}=20$ in each group). Judgment was classified into Unpleasant and Pleasant. Measurements of 11 smile attributes were done with ImageTool Version 3.0. These measurements were correlated with the type of judgment using the Pearson correlation coefficient.

Results: The two groups of evaluators showed no rating difference (analysis of variance, $P=0.64)$, thus they were placed into a single group. No significant correlation was found between esthetic judgment and six smile attributes (incisor exposure, interlabial gap, width 3 to 3 , smile index, right buccal corridor, and buccal corridor ratio). The control group showed more correlations with the unpleasant judgment type than the other groups.

Conclusion: Some correlations between smile attributes and esthetic judgment were found, but other features of smiles not evaluated in this study may interfere in smile attractiveness.

Keywords: esthetic, dental agenesis, attractiveness, dental implants, composite resin, perception

\section{Introduction}

A balanced symmetrical smile is considered essential in facial esthetics ${ }^{1,2}$ as it influences facial expression, general physical appearance, ${ }^{3}$ and the expression of emotions. Agenesis of the anterior teeth may affect the balance and symmetry of a smile, interfering negatively interpersonal relationships and self-esteem; ${ }^{4}$ the latter aspect is one of the main reasons patients with agenesis of the maxillary lateral incisors (LIs) seek treatment. ${ }^{5}$ This condition varies from $0.8 \%$ to $2 \%$ in the permanent dentition, being the most common type of agenesis. . $^{4,6,7,8}$

Recent studies on cosmetic dentistry assert that the proportion and shape of the teeth, proximal contact areas, and gingival zenith, among other factors, are desirable characteristics of an attractive smile., ${ }^{2,-11}$ To aid treatment planning, several studies have examined the relationship between dentofacial characteristics and smile 
attractiveness, looking for the threshold that demonstrates the degree of acceptance of alterations in esthetic parameters. ${ }^{12,13}$ Although some studies have associated dentofacial features with smile attractiveness, ${ }^{14,15}$ to the best of our knowledge, there are no studies investigating cases of agenesis of the LI treated with recontouring or implants.

Factors that influence positively the attractiveness of a smile are minimal gingival exposure, ${ }^{14,16-18}$ the smile line coinciding with the line of the inferior lip, and the thickness of the lips..$^{10,13,15,18,19}$ On the other hand, little exposure of the teeth, ${ }^{10}$ exposure of the lower incisors, ${ }^{10,14}$ wide buccal corridor, ${ }^{13,20}$ deviations of the midline, and asymmetrical teeth or gingival margins may interfere with smile attractiveness negatively. ${ }^{12,16,21}$

The purpose of the present study was to relate smile attractiveness with dentofacial characteristics of patients without agenesis (control) and patients with unilateral or bilateral agenesis of maxillary LIs treated with recontouring of the canines or implants.

\section{Materials and methods}

The study was approved by the University Ethics Committee (Protocol 010800093000-08). Patients with unilateral and bilateral LI agenesis were selected from the archive of the Department of Dentistry at State University of Maringá, Brazil. Selection criteria were congenital agenesis of the maxillary LIs, only one absent tooth in each maxillary quadrant, no treatment with prosthesis to replace the missing LI, and orthodontic treatment before implant placement or recontouring of the canines. Sixty patients met the selection criteria and were contacted and informed of the study's objectives. Fourteen patients did not participate, either because they had moved to other regions or did not want to participate.

The participants $(\mathrm{N}=46)$ were divided into two groups (Table 1): the Space Closure and Recontouring group (SCR, $\mathrm{N}=26$ ), which was treated with space closure due to the mesial drift of the canines and recontouring of the anterior teeth using composite resin, and the Space Opening and Implant Placement group (SOI, $\mathrm{N}=20$ ), treated by opening

Table I Distribution of sample according to gender and incidence of maxillary lateral incisor agenesis in SCR, SOI and CG groups

\begin{tabular}{lllllll}
\hline Group & \multicolumn{2}{l}{ Gender (n/\%) } & \multicolumn{3}{l}{ Agenesis (n/\%) } & \\
\cline { 2 - 6 } & Female & Male & $\boldsymbol{P}$ & Unilateral & Bilateral & $\boldsymbol{P}$ \\
\hline SCR & $20(76.92 \%)$ & $6(23.08 \%)$ & $9(34.62 \%)$ & $17(63.58 \%)$ & \\
SOI & $17(85 \%)$ & $3(15 \%)$ & 0.48 & $10(50 \%)$ & $10(50 \%)$ & 0.37 \\
CG & $15(68.18 \%)$ & $7(31.82 \%)$ & Not applicable & \\
\hline
\end{tabular}

Abbreviations: CG, control group; SCR, Space Closure and Recontouring; SOI, Space Opening and Implant Placement. the space corresponding to the LIs and placing implants at the site. Age varied from 14.10 to 41.10 years old for the SCR $(M=24.95)$, and from 19.02 to 45.08 for the SOI $(\mathrm{M}=25.12)$. In patients from both groups, treatment had finished between 6 months and 11 years at the time the data were gathered. A Mann-Whitney test revealed no significant mean differences $(P=0.89)$ in treatment time between SCR $(3.90 \pm 3.48$ years) and SOI $(3.54 \pm 2.39)$.

Patients without agenesis formed the control group (CG, $\mathrm{N}=22$ ), and were selected among undergraduate dentistry students at the State University of Maringá. Age in this group varied from 19.07 to 26.12 years old $(\mathrm{M}=21.30)$. The selection criteria were no orthodontic or orthopedic treatment; the presence of all permanent teeth (except third molars); no skeletal predicaments and good dental alignment; no restorations of the maxillary anterior teeth that could affect their relative size; and no laminate veneers or other types of prosthesis. In addition, patients from the $\mathrm{CG}$ and experimental groups should not have anterior diastema, occlusal and proximal wear, or gingival recession in the anterior teeth.

\section{Photographs}

Participants were photographed with posed smiles ${ }^{22}$ of the lower third of the face (subnasale to soft-tissue menton) ${ }^{2}$ at a distance of $1 \mathrm{~m}$. A single operator took the photographs, with the operator and patients at the same height, using a digital camera (Nikon D50, Nikon Corporation, Japan) mounted on a tripod stand, with a $60 \mathrm{~mm}$ macro objective lens (Nikon Corporation, Japan) and a ring flash (EM-140DG, Sigma, Japan).

Patients were photographed in a natural head position and an upright posture, with the eyes focused on an imaginary point at eye level. Several photographs were taken of each patient to obtain the most spontaneous and natural smile possible ${ }^{23}$ so that the most pleasant smile could be selected as the sample for evaluation. ${ }^{24}$

The photographs were then transferred to a computer and Adobe Photoshop CS2 (San Jose, CA, USA) was used to crop the photos and show only the lower third of the face. Most of the nose, cheeks, and chin were eliminated in order to minimize the influence of background facial attractiveness (Figure 1). ${ }^{15,21}$ No attempt to manipulate the image was performed, and all photos $(\mathrm{N}=68)$ were adjusted to the same size $(17 \mathrm{~cm} \times 10 \mathrm{~cm})$.

\section{Smile attractiveness according to laypersons and dentists}

The 68 photos were randomized and converted into a video using ProShow (Photodex Corporation, Austin, USA). They 


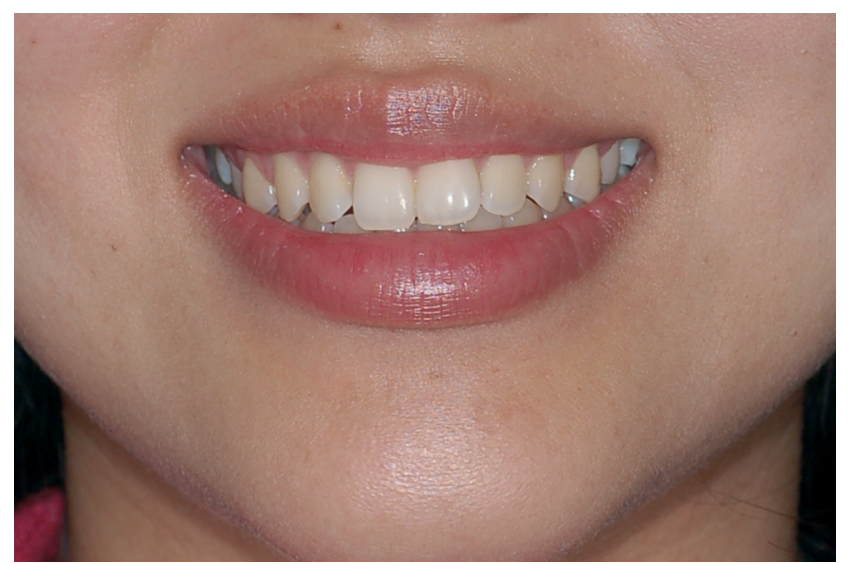

Figure I A standardized smile image showing only the inferior third of the face, from the sub-nasal point to the menton. An example of the patient from SOI group (lateral incisor agenesis unilateral - tooth 22).

were presented to two groups of evaluators: laypersons and dentists. The lay group (10 men and 10 women; mean age $=30.01 \pm 4.11)$ had university degrees, but no dentistry education of any form. The specialist group consisted of general dental practitioners (10 men and 10 women; mean age $=33.10 \pm 5.08$ ) with over four years of clinical experience. The independent samples $t$-test revealed no significant difference in age between laypersons and dentists $(P=0.08)$.

Evaluations were performed individually on a single laptop computer. Evaluators rated the smile for attractiveness on a $100-\mathrm{mm}$ Visual Analog Scale (VAS) ${ }^{23}$ and were asked to ignore other facial aspects, including skin color, freckles, and facial hair. The left end of the VAS indicated completely dissatisfied with the smile, whereas the right end indicated completely satisfied..$^{25}$

Each screen showing the photo was followed by a screen asking for the answer, both shown for five seconds, and the evaluators could not return to the previous images. The answers were recorded on a notepad that contained the VAS ${ }^{23}$ corresponding to the number of the photograph. Evaluators' scores were measured in millimeters, using a ruler, from their indication on the VAS to the left end of the scale (the least attractive point). The variable smile esthetic judgment was classified as unpleasant for VAS values from 0 to $\leq 50.99 \mathrm{~mm}$ and as pleasant when ratings varied from $\geq 51$ to $100 \mathrm{~mm}$.

\section{Esthetic dentofacial evaluation}

Quantitative measurements were taken over the images of the posed smiles, focusing on features previously deemed important to esthetics. ${ }^{15}$ Eleven attributes of the smile were measured, in millimeters, using ImageTool Version 3.0
(San Antonio, Texas). The tool used for measuring the attributes had been previously calibrated by measuring the actual width and length of the right central incisor (CI) on plaster models. The measurements were taken twice within a period of one month, and paired samples $t$-tests revealed no significant differences between them.

The smile attributes were classified into 11 features, as described by McNamara et al. ${ }^{15}$

1. Maximum incisor exposure (incisor exposure): The measure of the vertical display of the maxillary right CI.

2. Upper lip drape: The measure of the vertical coverage of the maxillary right CI by the upper lip (or the measure of the gingival display if the value is negative).

3. Lower lip to maxillary incisor (lower lip to incisor): The vertical measure from the deepest midline point on the superior margin of the lower lip to the edge of the maxillary right $\mathrm{CI}$.

4. Interlabial gap: The measure of the most inferior part of the tubercle of the upper lip to the deepest midline point on the superior margin of the lower lip.

5. Width of all visible maxillary teeth (width of visible teeth): The measure between the distal aspect of the most posterior visible tooth on the right and the most posterior visible tooth on the left side of the maxilla.

6. Maxillary intercanine width (width 3 to 3 ): The measure between the distal aspect of the right canine and the distal aspect of the left canine.

7. Smile index: The proportion of smile width/interlabial gap.

8/9. Right and left buccal corridors (RBC/LBC): The horizontal measure between the distal part of the canine and the respective outer commissure.

10. Smile width: The measure between the outer commissure and the outer commissure on smile.

11. Buccal corridor ratio (BC ratio): Proportion of intercanine width/smile width.

In order to verify the reliability of the method, internal consistency and inter-rater reliability were analyzed with Cronbach's $\alpha$ and intraclass correlation (ICC) statistics. For all participants $(\mathrm{N}=68)$, both Cronbach's $\alpha$ and ICC were 0.96 for the laypersons and 0.97 for the dentists. Further analysis revealed that within the three groups, both Cronbach's $\alpha$ and ICC were the same for laypersons (SCR, 0.91; SOI, 0.89; CG, 0.92) and for dentists (SCR, 0.92 ; SOI, $0.89 \mathrm{CG}, 0.97)$. That is, the coefficients indicate a high level of consistency among the evaluators' ratings on smile esthetic judgment between the two assessments. 
For this reason, statistical analysis was based on evaluators' first scores.

The scores given by the laypersons and the dentists were not statistically different (multifactorial analysis of variance, $P=0.64$ ), which is the reason that the two groups of evaluators were joined into a single group.

The 11 smile attributes were correlated with the type of judgment (pleasant and unpleasant) using the Pearson correlation coefficient ( $\mathrm{r}$ ), with results expressed in terms of means and standard deviations (SD). All statistical analyses were performed using SPSS 17.0 for Windows (SPSS, Chicago, IL), with the alpha level set at $P<0.05$.

\section{Results}

Descriptive statistics for the smile esthetic judgment and all smile attributes are shown in Table 2. The means of the smile esthetic judgments, as measured by the VAS, were higher for the pleasant type of judgment than for the unpleasant one, with the highest values in the SOI group and the lowest in the SRC group. Some measurements were consistent among the three groups, such as the means of incisor exposure, around $7 \mathrm{~mm}$, and the means of buccal corridor ratio, around $0.95 \mathrm{~mm}$, for all groups except the unpleasant type of judgment in the SOI group. Some means showed little variation among the groups, such as the width of visible teeth, which varied between $47.21 \mathrm{~mm}$ and $51.81 \mathrm{~mm}$, and the left buccal corridor, which varied between $1.19 \mathrm{~mm}$ and $1.58 \mathrm{~mm}$. In contrast, the means of the remaining attributes varied considerably: gingival display showed more negative than positive values - four out of six; lower lip to incisor varied from $1.35 \mathrm{~mm}$ to $2.67 \mathrm{~mm}$; interlabial gap from $8.78 \mathrm{~mm}$ to $10.47 \mathrm{~mm}$; width of visible teeth from $47.21 \mathrm{~mm}$ to $51.91 \mathrm{~mm}$; intercanine width from $58.81 \mathrm{~mm}$ to $63.82 \mathrm{~mm}$; smile index from $6.20 \mathrm{~mm}$ to $7.05 \mathrm{~mm}$; right buccal corridor from $1.00 \mathrm{~mm}$ to $1.57 \mathrm{~mm}$; and smile width from $49.90 \mathrm{~mm}$ to $54.37 \mathrm{~mm}$ (Table 2).

Correlation between the means of the smile esthetic judgments and those of the attributes of the smile (Table 3 ) revealed no significance for six smile attributes (incisor exposure, interlabial gap, width 3 to 3, smile index, right buccal corridor, and buccal corridor ratio). On the other hand, six associations were found: for the unpleasant type of judgment, there was correlation with the width of visible teeth and the left buccal corridor in the CG, with the left buccal corridor in the SCR group, and the lower lip to incisor in the SOI group. For the pleasant type of judgment, there was a correlation with smile width in the CG and lower lip to incisor in the SOI group.

\section{Discussion}

Dental agenesis in the maxillary anterior region impacts smile balance and symmetry. ${ }^{1}$ Treating the problem requires an interdisciplinary approach aimed at rehabilitating the smile, both in terms of function and esthetics. ${ }^{9-11,26}$ Two types of treatment are described for congenital agenesis of the LI: space closure with mesial repositioning of the canine, followed by tooth recontouring; or space opening followed by the placement of a prosthesis, transplant, or dental implant. ${ }^{27}$ The knowledge regarding craniofacial growth and detailed orthodontic treatment is fundamental as it assists correct teeth

Table 2 Descriptive statistics (mean [SD]) for smile esthetic judgment and smile attribute measurements (in mm) for the Control Group (GC), the Space Closure and Recontouring group (SCR) and the Space Opening and Implant placement group (SOI)

\begin{tabular}{|c|c|c|c|c|c|c|}
\hline \multirow[t]{2}{*}{ Attributes of smile } & \multicolumn{2}{|l|}{ GC } & \multicolumn{2}{|l|}{ SRC } & \multicolumn{2}{|l|}{ SOI } \\
\hline & $\begin{array}{l}\text { Unpleasant } \\
(n=\mid 4) \\
\text { mean }[S D]\end{array}$ & $\begin{array}{l}\text { Pleasant } \\
(n=8) \\
\text { mean [SD] }\end{array}$ & $\begin{array}{l}\text { Unpleasant } \\
(n=I 7) \\
\text { mean }[S D]\end{array}$ & $\begin{array}{l}\text { Pleasant } \\
(n=9) \\
\text { mean [SD] }\end{array}$ & $\begin{array}{l}\text { Unpleasant } \\
(n=I 5) \\
\text { mean [SD] }\end{array}$ & $\begin{array}{l}\text { Pleasant } \\
(n=5) \\
\text { mean [SD] }\end{array}$ \\
\hline Mean Judgment (VAS) & $44.18[5.46]$ & $55.98[3.58]$ & $33.92[10.17]$ & $56.93[4.57]$ & $38.63[8.85]$ & $61.51[3.05]$ \\
\hline Incisor exposure & $7.57[1.56]$ & $7.72[1.15]$ & 7.69 [2.03] & $7.44[0.5 \mathrm{I}]$ & $7.22[1.75]$ & $7.28[0.74]$ \\
\hline Gingival display & $-2.16[1.54]$ & $-1.71[1.64]$ & $3.03[3.4 I]$ & $\mathrm{I} .80[5.08]^{*}$ & $-3.03[2.30]$ & $-2.5 \mathrm{I}[0.97]$ \\
\hline Lower lip to incisor & $1.59[1.16]$ & $2.49[2.09]$ & $2.61[2.08]$ & $\mathrm{I} .35[0.82]$ & $2.67[1.63]^{*}$ & $2.21[1.19]$ \\
\hline Interlabial gap & $9.22[1.82]$ & $9.62[1.50]$ & $10.47[3.07]$ & 8.78 [0.94] & $9.90[1.33]$ & $9.50[0.91]$ \\
\hline Width of visible teeth & $50.35[4.26]^{*}$ & 51.91 [2.43] & $50.65[3.42]$ & 47.21 [3.43] & 49.21 [3.91] & $48.08[2.34]$ \\
\hline Width 3 to 3 & $63.25[5.45]$ & $63.82[2.70]$ & $61.52[5.44]$ & $60.02[2.89]$ & $60.27[4.73]$ & $58.81[3.15]$ \\
\hline Smile index & $7.05[1.12]$ & $6.76[0.93]$ & $6.32[1.74]$ & $6.90[0.73]$ & $6.20[0.97]$ & $6.24[0.68]$ \\
\hline Right buccal corridor & $1.49[0.50]$ & I.28 [0.43] & $\mathrm{I} .40[0.98]$ & $1.00[0.55]$ & $\mathrm{I} .57[0.77]$ & 1.35 [0.59] \\
\hline Left buccal corridor & $1.27[0.38]^{*}$ & $\mathrm{I} .24[0.45]$ & $\mathrm{I} .24[\mathrm{I} .3 \mathrm{I}]^{*}$ & $\mathrm{I} .30[0.43]$ & $\mathrm{I} .58[0.67]$ & I. 19 [0.45] \\
\hline Smile width & $52.84[4.39]^{*}$ & $54.37[1.96]^{*}$ & $53.49[3.72]$ & $49.90[3.44]$ & $52.82[4.99]$ & $50.65[2.64]$ \\
\hline Buccal corridor ratio & $0.95[0.02]$ & $0.95[0.01]$ & $0.95[0.03]$ & $0.95[0.01]$ & $0.93[0.04]$ & $0.95[0.02]$ \\
\hline
\end{tabular}

Note: *Smile attribute measurements that showed correlations with type of judgment. $P<0.05$. Abbreviation: VAS, Visual Analog Scale. 
Table 3 Pearson's $r$ correlations between attributes of the smile and type of judgment

\begin{tabular}{llll}
\hline Group & $\begin{array}{l}\text { Type of } \\
\text { judgment }\end{array}$ & $\begin{array}{l}\text { Attributes } \\
\text { of the smile }\end{array}$ & $\boldsymbol{r} / \mathbf{P}$ \\
\hline CG & Unpleasant & Width of visible teeth & $-0.557 / 0.038$ \\
& & Left buccal corridor & $0.609 / 0.021$ \\
& & Smile width & $-0.578 / 0.030$ \\
& Pleasant & Smile width & $-0.787 / 0.020$ \\
SCR & Unpleasant & Left buccal corridor & $-0.588 / 0.013$ \\
& Pleasant & Gingival display & $-0.681 / 0.043$ \\
SOI & Unpleasant & Lower lip to incisor & $-0.550 / 0.033$ \\
\hline
\end{tabular}

Abbreviations: CG, control group; SCR, Space Closure and Recontouring; SOI, Space Opening and Implant Placement.

positioning in both types of treatment and helps to improve the volume of the alveolar ridge for the implant placement. ${ }^{28,29}$ Several studies have assessed these two treatment options, ${ }^{30-32}$ and others revealed the opinion of dentists and laypersons concerning smile attractiveness. ${ }^{12,23}$ However, as far as we know, no study has examined whether smile attributes can interfere in the smile attractiveness of patients with LI agenesis treated with recontouring or implants.

The present study found no significant correlations between smile esthetic judgment and six smile attributes (incisor exposure, interlabial gap, width 3 to 3, smile index, right buccal corridor, and buccal corridor ratio) for all three groups.

On the other hand, a negative correlation was found between gingival display and a pleasant smile for the SCR group. In other words, the larger the gingival display, the less pleasant the smile is. Forty-seven out of 68 patients had gingival display above the cervical margin of the maxillary right CI. This finding is similar to previous studies showing that little gingival exposure makes the smile appear more attractive. ${ }^{15,16,18}$ Although the acceptable range for gingival exposure varies by study, Kokich et $\mathrm{al}^{16}$ showed that smiles with no gingival exposure were more attractive to orthodontists than smiles with 2-mm exposure; in constrast, general dental practitioners and laypersons were more tolerant with the level of gingival exposure - only exposure of $4 \mathrm{~mm}$ was classified as excessive. Dentists should be careful with gingival display at the conclusion of treatments, particularly in cases of space closure because of the individual character of orthodontic treatment in these cases.

Negative correlations were found between smile esthetic judgment and lower lip to incisor for the SOI group, which indicates that as the distance between the lower lip and the edge of the upper incisors decreases, the more unpleasant the smile becomes. This finding diverges from previous studies that showed that a consonant smile arc with no exposure of the lower incisors is more attractive than a nonconsonant arc. ${ }^{10,13,14,22}$ The arc of the maxillary incisal edges can be altered with therapeutic measures - either orthodontically or with restorative treatment. In orthodontics, the brackets can be positioned in such a way as not to disturb the existing consonance or to create a consonant smile, so that a parallel smile arc relationship is created - an attractive relationship. ${ }^{22}$ Restorative recontouring of teeth can decrease the distance between the lower lip and the incisor. Patients with major vertical growth tend to show greater distance between the lower lip and incisors. ${ }^{33}$

Correlations were found between unpleasant smile judgment and left BC for both the CG and the SCR group, although the direction of the correlations was different between the groups - positive for the former and negative for the latter. The width of the BC and its impact on smile attractiveness is a disputed issue. ${ }^{24}$ Some studies show that $\mathrm{BCs}$ have no influence on the evaluations of esthetic smiles, ${ }^{14,15,22,34}$ whereas other studies show that a narrow BC correlates with more pleasing smiles. ${ }^{13,35}$ This study expected to find a wider BC in the SCR group due to space closure by mesial drifting, but the range of $\mathrm{BC}$ ratio was similar for all groups, with no statistical difference.

Smile width showed an unexpected negative correlation for both pleasant and unpleasant types of judgment in the CG. Although research ${ }^{20}$ shows that both orthodontists and dentistry students find broader smiles more attractive, the present study found contradictory results, and is thus inconclusive with regard to the influence of this parameter on smile esthetic judgment. Larger smile width means were found in the $\mathrm{CG}$, and although the results of the correlations are conflicting, larger smile width was indeed expected in the $\mathrm{CG}$, as patients with agenesis show simplified morphology and reduced arch diameter.

Negative correlation was found between unpleasant smile judgment and width of visible teeth for the CG group, similarly to Martin et al (2007). ${ }^{35}$ These authors found that laypersons tended to prefer smiles that displayed teeth from second premolar to second premolar (10 teeth), whereas orthodontists preferred smiles that displayed teeth from molar to molar (12 teeth). That is, smiles with a broader width of visible teeth tend to be considered more pleasant.

The CG showed more correlations with unpleasant smile judgment than did the other groups. Despite the criteria for selection of the participants in the $C G$, they were not verified for esthetic parameters that could standardize their smiles, such as the golden proportion. This greater association with 
unpleasant smile judgment was expected because these patients had not undergone any orthodontic or esthetic dentistry treatment.

It is important to keep in mind that studies on smile attractiveness have some limitations. On one hand, the use of photographs for the evaluation of smile attractiveness provides the validity and reliability that the research method requires. ${ }^{36}$ On the other hand, ratings vary according to what is shown to the evaluators - a photograph of a face is considered more attractive than a photograph of the lower third of a face, which in turn is more attractive than an intra-oral photograph. ${ }^{23}$ In this study, the scores of the photographs of the lower third of the face were 47.46 for the laypersons and 45.02 for the dentists, similar to the results of Flores-Mir et al (2004), ${ }^{23}$ who found a mean of 43.1 for photographs of the same type. In addition, skin color and the shape of the lips can interfere in the perception of smile attractiveness in photographs of the lower third of the face. Another limitation lies in the use of the VAS; despite being considered a convenient and reliable method in the evaluation of dental-facial esthetics, ${ }^{20,21,25,30,34}$ evaluators seem to avoid the scale's far ends, regardless of their actual preferences. ${ }^{14}$ In addition, due to the subjective nature esthetic indices, they do not necessarily reveal the connection between malocclusion and psychosocial health. ${ }^{37}$

Studies on smile attractiveness have helped dentists to understand how people react to different attributes of the smile so that they can prioritize the patients' needs and desires, regardless of their own opinions. ${ }^{19}$ The present study aimed to find correlations between smile attributes and esthetic judgment, and although some were found, the authors believe that each attribute individually play a minimal role in the attractiveness of the smile. We also believe that perceived attractiveness is due to a combination of factors, such as teeth symmetry, arrangement, shade, proportion, and color; ${ }^{3}$ gingival architecture; and lip thickness, among others. ${ }^{16}$ Finally, we believe that associations between smile attributes and esthetic judgment can be easily found in cases of extremely deviant characteristics.

\section{Conclusion}

Based on the results, the following can be concluded:

1. No correlations were found between esthetic smile judgment and six smile attributes (incisor exposure, interlabial gap, width 3 to 3 , smile index, right buccal corridor, and buccal corridor ratio) for all groups.
2. The attributes of the smile that showed correlation with esthetic judgment were width of visible teeth, left buccal corridor, and smile width for the CG; left buccal corridor and gingival display for the SCR group; and lower lip to incisor for the SOI group.

3. Although some correlations between attributes of the smile and esthetic judgment have been found, other features of the smile not evaluated in this study may interfere in the smile attractiveness.

\section{Disclosure}

The authors report no conflicts of interest in this work.

\section{References}

1. Shaw WC, Rees G, Dawe M, Charles CR. The influence of dentofacial appearance on the social attractiveness of young adults. Am J Orthod. 1985;87(1):21-26.

2. Peck S, Peck L, Kataja M. The gingival smile line. Angle Orthod. 1992;62(2):91-100.

3. Van der Geld P, Oosterveld P, Van Heck G, Kuijpers-Jagtman AM. Smile attractiveness. Angle Orthod. 2007;77(5):759-765.

4. Araújo EA, Oliveira DD, Araújo MT. Diagnostic protocol in cases of congenitally missing maxillary lateral incisors. World $J$ Orthod. 2006;7:376-388.

5. Altug-Atac AT, Erdem D. Prevalence and distribution of dental anomalies in orthodontic patients. Am J Orthod Dentofacial Orthop. 2007;131:510-514.

6. Pinho T, Tavares P, Maciel P, Pollmann C. Developmental absence of maxillary lateral incisors in the Portuguese population. Eur J Orthod. 2005;27:457-460.

7. Vahid-Dastherdi E, Borzabadi-Farahani A, Mahdian M, Amini N. Non-syndromic hypodontia in an Iranian orthodontic population. J Oral Sci. 2010;52(3):445-461.

8. Gomes RR, da Fonseca JA, Paula LM, Faber J, Azevedo AC. Prevalence of hypodontia in orthodontic patients in Brasilia, Brazil. Eur J Orthod. 2010;32:302-306.

9. Morley J, Eubank J. Macroesthetic elements of smile design. JAm Dent Assoc. 2001;132:39-45.

10. Sarver DM, Ackermann MB. Dynamic smile visualization and quantification: part 2. Smile analysis and treatment strategies. Am J Orthod Dentofacial Orthop. 2003;124(2):116-127.

11. Magne P, Belser UC. Bonded porcelain restorations in the anterior dentition. A biometric approach. Chicago: Quintessence; 2002.

12. Kokich VG, Kiyak A. Perceptions of dental professionals and laypersons to altered dental esthetics: asymmetric and symmetric situations. $A m J$ Orthod Dentofacial Orthop. 2006;130:141-151.

13. Parekh SM, Fields HW, Beck M, Rosenstiel S. Attractiveness of variations in the smile arc and buccal corridor space as judged by orthodontists and laymen. Angle Orthod. 2006;76:557-563.

14. Schabel BJ, McNamara JA, Franchi L, Baccetti T. Q-sort assessment vs visual analog scale in the evaluation of smile esthetics. Am J Orthod Dentofacial Orthop. 2009;135:S61-S71.

15. McNamara L, McNamara JA Jr, Ackerman MB, Baccetti T. Hard- and soft-tissue contributions to the esthetics of the posed smile in growing patients seeking orthodontic treatment. Am J Orthod Dentofacial Orthop. 2008;133:491-499.

16. Kokich VO Jr, Kiyak HA, Shapiro PA. Comparing the perception of dentists and lay people to altered dental esthetics. J Esthet Dent. 1999;11:311-324.

17. Mackley RJ. An evaluation of smiles before and after orthodontic treatment. Angle Orthod. 1993;63:183-190. 
18. Hulsey CM. An esthetic evaluation of lip teeth relationships present in the smile. Am J Orthod Dentofacial Orthop. 1970;57:132-144.

19. Scott CR, Goonewardene MS, Murray K. Influence of lips on the perception of malocclusion. Am J Orthod Dentofacial Orthop. Ago 2006;130(2):152-162.

20. Ioi H, Nakata S, Counts AL. Effects of buccal corridors on smile esthetics in Japanese. Angle Orthod. 2009;79:628-633.

21. Pinho S, Ciriaco C, Faber J, Lenza MA. Impact of dental asymmetries on the perception of smile esthetics. Am J Orthod Dentofacial Orthop. 2007;132:748-753.

22. Krishnan V, Daniel ST, Lazar D, Asok A. Characterization of posed smile by using visual analog scale, smile arc, buccal corridor measures, and modified smile index. Am J Orthod Dentofacial Orthop. 2008;133: $515-523$.

23. Flores-Mir C, Silva E, Barriga MI, Lagravere MO, Major PW. Lay person's perception of smile aesthetics in dental and facial views. J Orthod. 2004;31:204-209.

24. Isiksal E, Hazar S, Akyalçin S. Smile esthetics: perception and comparison of treated and untreated smiles. Am J Orthod Dentofacial Orthop. 2006;129:8-16.

25. Chang M, Wennström JL, Ödman P, Andersson B. Implant supported single-tooth replacements compared to contralateral natural teeth. Crown and soft tissue dimensions. Clin Oral Impl Res. 1999;10:185-194.

26. Borzabadi-Farahani A. Orthodontic considerations for rehabilitation of patients with hypodontia using endosseous implants. J Oral Implantol. In Press 2011. Doi:10.1563/AAID-JOI-D-11-00022.

27. Rosa M, Zachrisson BU. Integrating space closure and esthetic dentistry in patients with missing maxillary lateral incisors. $J$ Clin Orthod. 2007;41:563-573.

28. Beyer A, Tausche E, Boening K, Harzer W. Orthodontic space opening in patients with congenitally missing lateral incisors: timing of orthodontic treatment and implant insertion. Angle Orthod. 2007;77:404-409.
29. Charmichael RP, Sandór GKB. Dental implants, growth of the jaws, and determination of skeletal maturity. Atlas Oral Maxillofac Surg Clin North Am. 2008;16:1-9.

30. Robertsson S, Mohlin B. The congenitally missing lateral incisor. A retrospective study of orthodontic space closure versus restorative treatment. Eur J Orthod. 2000;22:697-710.

31. Pini NIP, De-Marchi LM, Ramos AL, Furquim LZ, Pascotto RC. Width/length ratio and gingival zenith analysis in patients with bilateral agenesis of maxillary lateral incisors. Dental Press $J$ Orthod. 2012;17(5):87-93.

32. Pini NIP, De-Marchi LM, Gribel BF, Ubaldini ALM, Pascotto RC. Digital analysis of anterior dental esthetic parameters in patients with bilateral maxillary lateral incisor agenesis. $J$ Esthet Restor Dent. In press. 2012.

33. Manshaee K, Changizi S, Mojaver YN. Smiles and archform: a comparison study. Orthodontic Waves. 2008;67:60-64.

34. Roden-Johnson D, Gallerano R, English J. The effects of buccal corridor spaces and arch form on smile esthetics. Am J Orthod Dentofacial Orthop. 2005; 127:343-350.

35. Martin AJ, Buschang PH, Boley JC, Taylor RW, McKinney TW. The impact of buccal corridors on smile attractiveness. Eur J Orthod. 2007;29:530-537.

36. Howells DJ, Shaw WC. The validity and reliability of ratings of dental and facial attractiveness for epidemiologic use. Am J Orthod Dentofacial Orthop. 1985;88:402-408.

37. Borzabadi-Farahani A. A review of the evidence supporting the aesthetic orthodontic treatment need indices. Prog Orthod. 2012, doi:10.1016/j. pio.2012.03.003. In press 18 June 2012
Clinical, Cosmetic and Investigational Dentistry

\section{Publish your work in this journal}

Clinical, Cosmetic and Investigational Dentistry is an international, peer-reviewed, open access, online journal focusing on the latest clinical and experimental research in dentistry with specific emphasis on cosmetic interventions. Innovative developments in dental materials, techniques and devices that improve outcomes and patient satisfaction

\section{Dovepress}

and preference will be highlighted. The manuscript management system is completely online and includes a very quick and fair peerreview system, which is all easy to use. Visit http://www.dovepress. com/testimonials.php to read real quotes from published authors. 